\title{
Effect of Substitution of Al for Fe on Magnetic Properties and Particle Size of Ni-Co Nanoferrite
}

\author{
Ahmad Amirabadizadeh, Tyebeh Amirabadi \\ Department of Physics, Faculty of Science, University of Birjand, Birjand, Iran. \\ Email: ahmadamirabadi@yahoo.com \\ Received January $12^{\text {th }}, 2013$; revised June $9^{\text {th }}, 2013$; accepted June $22^{\text {nd }}, 2013$ \\ Copyright (C) 2013 Ahmad Amirabadizadeh, Tyebeh Amirabadi. This is an open access article distributed under the Creative Com- \\ mons Attribution License, which permits unrestricted use, distribution, and reproduction in any medium, provided the original work \\ is properly cited.
}

\begin{abstract}
Nanocrystalline $\mathrm{Al}$ doped nickel-cobalt ferrite $\left[\mathrm{Ni}_{0.6} \mathrm{Co}_{0.4} \mathrm{Fe}_{2-x} \mathrm{Al}_{x} \mathrm{O}_{4}(x=0.0,0.1,0.3,0.5\right.$ and 0.7$\left.)\right]$ powders have been synthesized by sol-gel auto-ignition method and the effect of non-magnetic aluminum content on the nanosize particles and magnetic properties has been studied. The X-ray diffraction (XRD) revealed that the powders obtained are single phase with inverse spinel structure. The calculated grain size from XRD data have been verified using transmission electron microscopy (TEM). TEM photograph shows that the powders consist of nano meter sized grain. The size of nanoparticles decreases as the non magnetic Al content increases. Magnetic hysteresis loops were measured at room temperature with maximum applied magnetic field of $20 \mathrm{KOe}$. As aluminum content increases, the measured magnetic hysteresis curves became narrow and saturation magnetization $\left(\mathrm{M}_{\mathrm{s}}\right)$, and coercive force $\left(\mathrm{H}_{\mathrm{c}}\right)$ decreased. The reduction of magnetization with the increase of aluminum content is caused by non-magnetic $\mathrm{Al}^{3+}$ ions and weakened interaction between sub-lattices.
\end{abstract}

Keywords: Sol-Gel; Particle Size; Magnetic Properties; Nickel-Cobalt Ferrite

\section{Introduction}

Magnetic nanoparticles are of great technological importance because of their use in magnetic fluid, information storage system, medical diagnosis and their interest in fundamental science, especially for addressing the fundamental relationships between magnetic properties and their crystal structure [1].

Recently, several methods were used to synthesize highly crystalline and uniformly sized magnetic nanoparticles of mixed ferrite $[2,3]$. Most of these methods cannot be applied to a large scale and economic productions, because they require expensive and toxic reagents, complicated synthetic steps, high reaction temperature and long reaction times.

Among many preparation techniques, sol-gel method stands out as an alternative and highly promising method of preparation. This method is quite simple, fast and inexpensive since it does not involve intermediate decomposition and do not need calcining steps. Moreover, it is easy to control the stoichiometry, which has important effect on the magnetic properties of the ferrite $[4,5]$.

The nanosized systems investigated herein are based on mixed nickel-cobalt spinel ferrites. Spinels are iso- structural with mineral spinel $\mathrm{MgAl}_{2} \mathrm{O}_{4}$ and crystallize in a face-centered cubic lattice with eight formula units in the cubic unit cell, belonging to the Fd-3m space group. Spinel ferrites have the general molecular formulas $\left(\mathrm{M}^{2+}\right)\left[\mathrm{Fe}_{2}^{3+}\right] \mathrm{O}_{4}^{2-}$ where $\mathrm{M}^{2+}$ and $\mathrm{Fe}^{3+}$ are the divalent and trivalent cations occupying tetrahedral (A) and octahedral (B) interstitial positions of the fcc lattice formed by $\mathrm{O}^{2-}$ ions. A whole range of distribution of cations is possible in spinel $\left(\mathrm{M}^{2+}\right)_{(1-x)}\left[\left(\mathrm{Fe}^{3+}\right)\left(\mathrm{M}^{2+}\right)_{x}\right.$ $\left.\left(\mathrm{Fe}_{(2-x)}^{3+}\right)\right] \mathrm{O}_{4}$, where the ions inside the brackets are said to occupy B sites and the ions outside the bracket occupy A sites; $x$ represents the so-called degree of inversion (defined as the fraction of A-site occupied by $\mathrm{Fe}^{3+}$ cation). In the above formula when $x=0$, it is called normal spinel. When $x=1$, it is called an inverse spinel. When $0<x<1$, it is called mixd spinel. In inverse spinel $\mathrm{Fe}_{\mathrm{A}}^{3+}\left[\mathrm{M}_{\mathrm{B}}^{2+} \mathrm{Fe}_{\mathrm{B}}^{3+}\right] \mathrm{O}_{4}$ with $\mathrm{M}^{2+}=\mathrm{Co}^{2+}, \mathrm{Ni}^{2+}$ and $\mathrm{Cu}^{2+}$, all divalent metal ions occupy octahedral (B) sites and $\mathrm{Fe}^{3+}$ ion is distributed on both tetrahedral (A) and octahedral (B) sites. 
In the present work, a wet chemical method known as sol-gel method has been used to produce $\mathrm{Ni}_{0.6} \mathrm{Co}_{0.4} \mathrm{Fe}_{2-x}$ $\mathrm{Al}_{x} \mathrm{O}_{4}(x=0.0,0.1,0.3,0.5$ and 0.7$)$ nanoferrites and discuss the result of structural, magnetic properties and size particles due to substitution of $\mathrm{Al}^{3+}$ for $\mathrm{Fe}^{3+}$ on (A) and (B) sites of spinel structure, where the investigation of aluminum substitution nickel-cobalt ferrite was not documented yet.

\section{Experimental}

\subsection{Synthesis Technique}

Nanocrystalline powders of $\mathrm{Ni}_{0.6} \mathrm{Co}_{0.4} \mathrm{Fe}_{2-x} \mathrm{Al}_{x} \mathrm{O}_{4}(x=0.0$, $0.1,0.3,0.5$ and 0.7$)$ were prepared by sol-gel auto-ignition method. The A.R grade Citric acid $\left(\mathrm{C}_{6} \mathrm{H}_{8} \mathrm{O}_{7}\right)$, Nickel nitrate $\left(\mathrm{Ni}\left(\mathrm{NO}_{3}\right)_{2} \cdot 6 \mathrm{H}_{2} \mathrm{O}\right)$, Cobalt nitrate $\left(\mathrm{Co}\left(\mathrm{NO}_{3}\right)_{2} \cdot 6 \mathrm{H}_{2} \mathrm{O}\right)$, Aluminum nitrate $\left(\mathrm{Al}\left(\mathrm{NO}_{3}\right)_{3} \cdot 9 \mathrm{H}_{2} \mathrm{O}\right)$, Ferric nitrate

$\left(\mathrm{Fe}\left(\mathrm{NO}_{3}\right)_{3} \cdot 9 \mathrm{H}_{2} \mathrm{O}\right)$ were used as starting materials. The molar ratio of metal nitrates to citric acid was takes as $1: 1$. The metal nitrates were dissolved together in a minimum amount of de-ionized water to get clear solution. An aqueous solution of citric acid was mixed with metal nitrates solutions, and then ammonia solution was slowly added to adjust the $\mathrm{pH}$ at 7 . The mixed solution was moved on to a hot plate with continuous stirring at $80^{\circ} \mathrm{C}$. During evaporation, the solution became viscous and finally formed a very viscous brown gel. When finally all remaining water was released from the mixture, the sticky mass began to bubble. After several minutes the gel automatically ignited and burnt with glowing flints. The decomposition reaction would not stop before the whole citrate complex was consumed. The auto-ignition was completed within a minute, yielding the browncolored ashes termed as a precursor. The as-prepared powders of all the samples were heated at $600^{\circ} \mathrm{C}$ for 2 hours in air to get the final products.

\subsection{X-Ray Diffraction}

The structural characterization of the ferrite powders asprepared was carried out using bruker D8-Advance XRD system with $\mathrm{Cu} \mathrm{K} \mathrm{K}_{\alpha}$ radiation (wave length $\lambda=0.15406$ $\mathrm{nm}$ ). The average particle size $D$ was calculated using most intense peak (311) employing the scherrer's formula [6]

$$
D=\frac{K \lambda}{\beta \cos \theta}
$$

where $\beta$ is the angular line width at half maximum intensity and $\theta$ is the Bragg's angle for the actual peak.

\subsection{TEM}

To verify the particle size calculating using XRD data, TEM studies were carried out using Philips CM-12 transmission electron microscope (TEM).

\subsection{TG-DTA}

In order to investigation the spinel ferrite phase formation, the dried powders were characterized via thermogravimetric (TG) and differential analysis (DTA) using model of Pyirf-diamond TG-DTA instrument, at a heating rate $10^{\circ} \mathrm{C} / \mathrm{min}$ in static air.

\subsection{Magnetic Measurements}

Magnetic measurements were performed using the commercial Lake-shore 7400 vibrating sample magnetometer (VSM). Magnetic hysteresis loops were measured of room temperature with maximal applied magnetic fields up to $20 \mathrm{KOe}$. The saturation magnetization $\left(\mathrm{M}_{\mathrm{s}}\right)$ and coercivity $\left(\mathrm{H}_{\mathrm{c}}\right)$ were found from hysteresis loops.

\section{Results and Discussions}

\subsection{Structural Characterization}

Figure 1 shows the powder $\mathrm{X}$-ray diffractographs of $\mathrm{Ni}_{0.6} \mathrm{Co}_{0.4} \mathrm{Fe}_{2-x} \mathrm{Al}_{x} \mathrm{O}_{4}(x=0.0,0.1,0.3,0.5$ and 0.7$)$ samples. The XRD patterns clearly indicate that the prepared samples contain cubic spinel structure [7]. A close examination of XRD patterns reveal that the diffraction peaks became broader with increasing aluminum content $x$, which may be due to distribution of nanocrystallinity. The sizes of crystallites in the samples were evaluated by measuring the FWHM of the most intense peak (311). The results are shown in Table 1. Further, it is observed from Table 1 that particle size decrease in non-magnetic Al substitution. The same trend in variation of crystallite size was observed in $\mathrm{Mn}-\mathrm{Zn}$ ferrite ferrofluids prepared by chemical synthesis [8].

The values for lattice constants were obtained for all the samples using XRD data with an accuracy of \pm 0.0002 $\AA$. The values of lattice constants are listed in Table 1. It

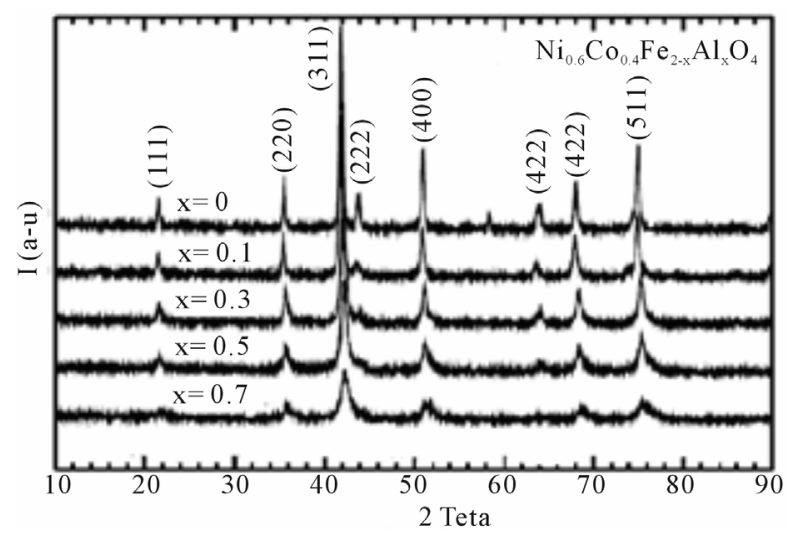

Figure 1. X-ray diffraction pattern of $\mathrm{Ni}_{0.6} \mathrm{Co}_{0.4} \mathrm{Fe}_{2-x} \mathrm{Al}_{x} \mathrm{O}_{4}(x$ $=0.0,0.1,0.3,0.5$ and 0.7 ) samples. 
is observed from Table $\mathbf{1}$, that the lattice constant decreases with increasing $\mathrm{Al}$ content $x$. This behavior of lattice constant with aluminum content $\mathrm{x}$ is explained on the basis of difference in ionic radii of $\mathrm{Fe}^{3+}$ and $\mathrm{Al}^{3+}$. In the present series larger $\mathrm{Fe}^{3+}(0.67 \AA)$ ions are replaced by smaller $\mathrm{Al}^{3+}(0.51 \AA)$ ions; therefore decrease in lattice constant takes places. Similar trend was found in $\mathrm{Cu}-$ Cd ferrite with aluminum substitution [9].

The addition of $\mathrm{Al}^{3+}$ ion which has strong preference for all the octahedral sites should exhibit the decrease of the magnetization because the ion is non-magnetic. It is observed that increasing the amount of $\mathrm{Al}$, the magnetic moment of unit cell decreases [9]. They have found that the canting angle increases with increase of the Al content, which indicates the favoring of triangular spin moment at the octahedral site leading to reduction in the sub-lattice interaction. The removal of magnetic $\mathrm{Fe}^{3+}$ ion from magnetic sub-lattice and substitution of the nonmagnetic $\mathrm{Al}^{3+}$ ion in its place weakens the super-exchange interactions, which tend to align the neighboring dipoles antiparallelly. Hence, the structural and magnetic properties are closely interconnected.

Figure 2 present the TEM photograph of $x=0$ sample, which show that the particle sizes in nanometers agree with XRD data.

\subsection{Thermal Analysis}

In order to investigate the formation of the spinel structure phase, thermal analysis for the sample $x=0$ is carried out in the temperature range $100^{\circ} \mathrm{C}$ to $500^{\circ} \mathrm{C}$ in static air at $10^{\circ} \mathrm{C} / \mathrm{min}$.

Figure 3 shows TG-DTA for precursor nickel-cobalt ferrite powder. The TG-DTA shows the presence of one exothermic peak at $303^{\circ} \mathrm{C}$ which may be due to reaction of citric acid and metal nitrates with total weight loss around $6 \%$. The exothermic peak at $303^{\circ} \mathrm{C}$ indicates the

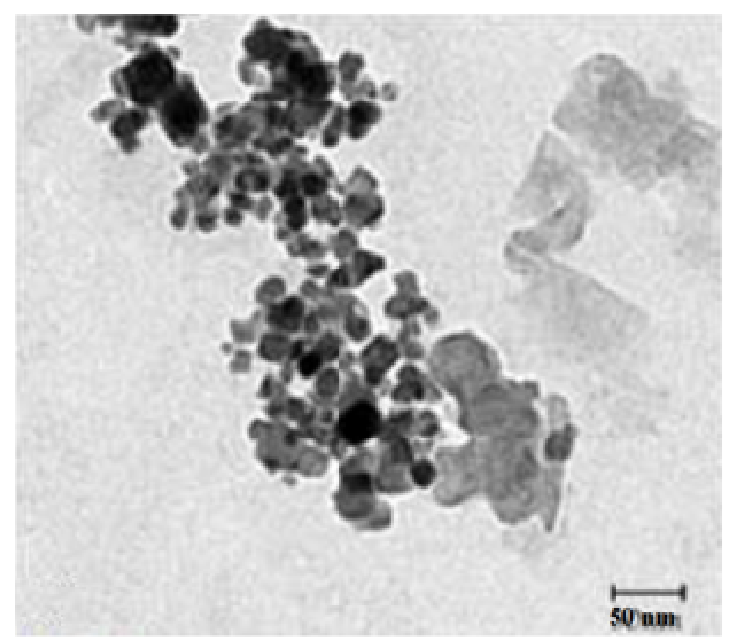

Figure 2. TEM photograph for $\mathrm{Ni}_{0.6} \mathrm{Co}_{0.4} \mathrm{Fe}_{2} \mathrm{O}_{4}$.

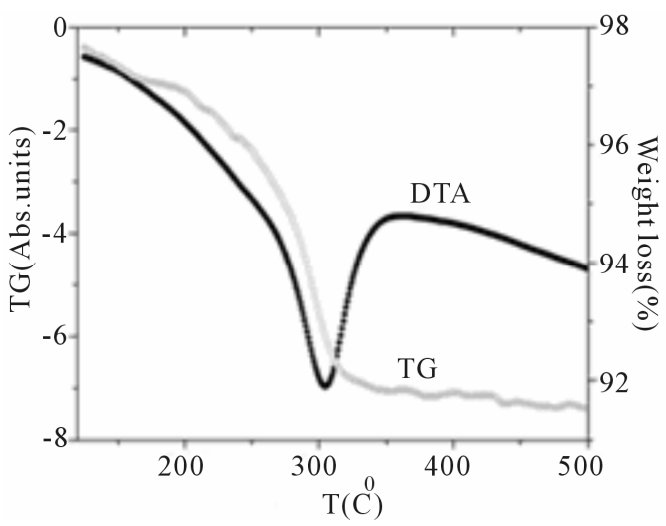

Figure 3. TG-DTA of $\mathrm{Ni}_{0.6} \mathrm{Co}_{0.4} \mathrm{Fe}_{2} \mathrm{O}_{4}$.

formation of crystallization of the ferrite phase. It may be mentioned that the formation of the spinel phase is at a lower temperature than $303^{\circ} \mathrm{C}$ while thermal analysis is a dynamic process. Thus the temperature recorded by TG-DTA for spinel formation is expected to be higher. It is observed from acetate-citrate gelation method [10], that above $430^{\circ} \mathrm{C}$ only the organics are removed completely, and the prediction of the particle size and further analysis is irrelevant below this temperature. Therefore even though the decomposition has completed at $303^{\circ} \mathrm{C}$, we have chosen $600^{\circ} \mathrm{C}$ as final calcination temperature for this samples. The preparation of ferrites around this temperature is confirmed by XRD data.

\subsection{Magnetic Properties}

Magnetic hysteresis loops of aluminum doped nickelcobalt ferrite $\mathrm{Ni}_{0.6} \mathrm{Co}_{0.4} \mathrm{Fe}_{2-x} \mathrm{Al}_{x} \mathrm{O}_{4}(x=0.0,0.1,0.3,0.7$ and 0.7) nanoparticles measured at room temperature using VSM are shown in Figures 4(a)-(e). As observed from Figure 4 the hysteresis loops become narrow as the aluminum content $\mathrm{x}$ increases. At maximal applied magnetic field of $20 \mathrm{KOe}$ the saturation was achieved. It is obvious that the magnetization at this field (saturation of magnetization, $\mathrm{M}_{\mathrm{s}}$ ) is decreasing as $\mathrm{x}$ increases. The results of our measurements presented in Table 1 and show that with increasing $\mathrm{Al}$ content $\mathrm{x}$ the saturation magnetization $\mathrm{M}_{\mathrm{s}}$ and coercive field $\mathrm{H}_{\mathrm{c}}$ all decrease. There are more evidences of change in magnetization with the change of nanoparticles size, with a general conclusion that in smaller particles the reduction of magnetization is more pronounced [4]. Magnetization reduction was connected to cation redistribution (reduced concentration of iron cations on tetrahedral sites) and to spin non collinearity [11].

The coercive field decreases generally with decreasing of particle size. It is observed that the anisotropy field decreases with increasing $\mathrm{Al}^{3+}$ concentration, which leads to decrease in coercivity [12]. In our case, the coercivity decrease is the combination of the size reduction 


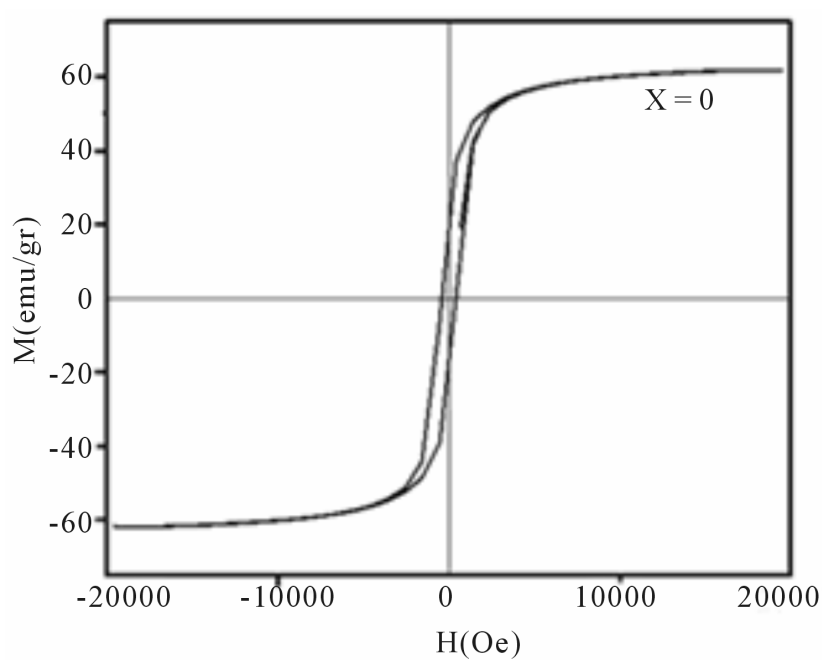

(a)

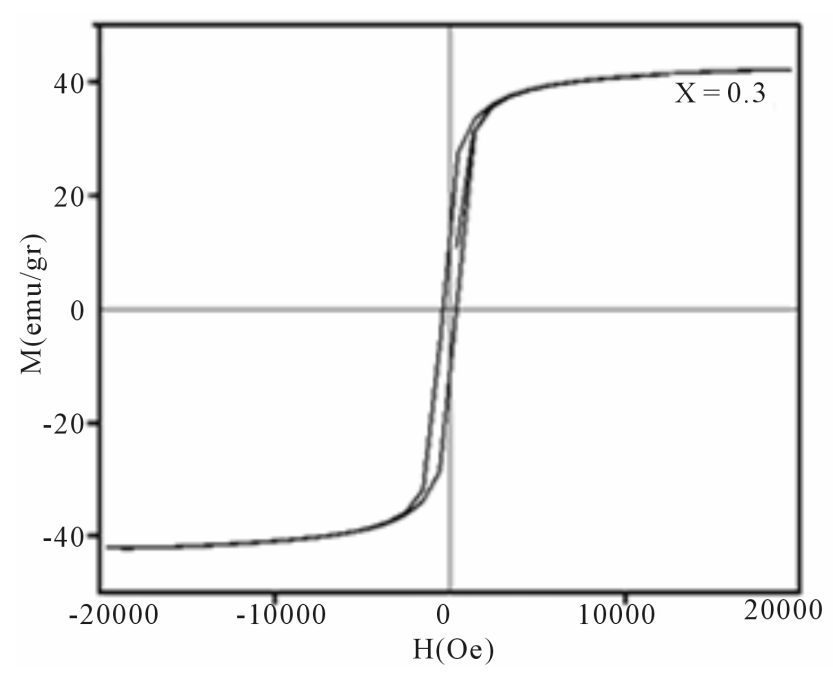

(c)

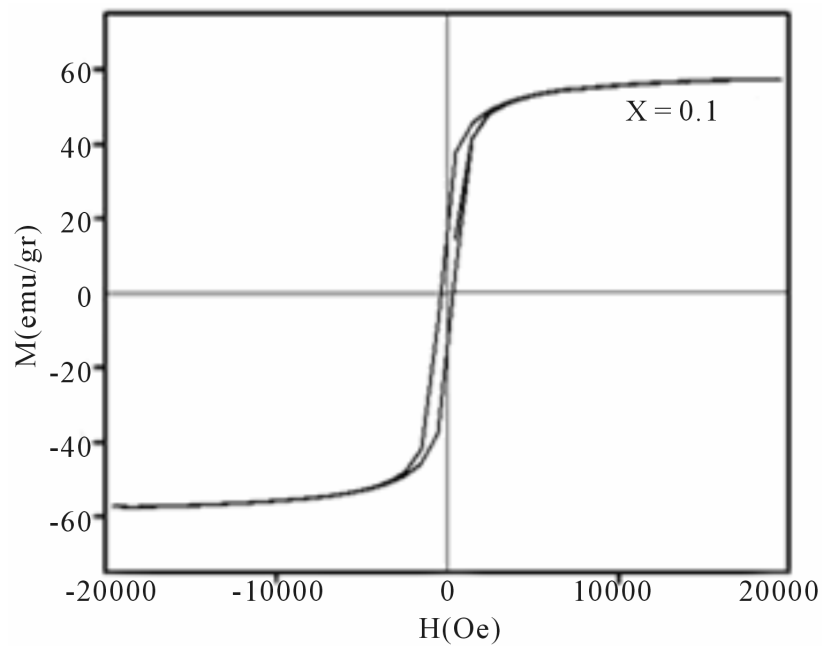

(b)

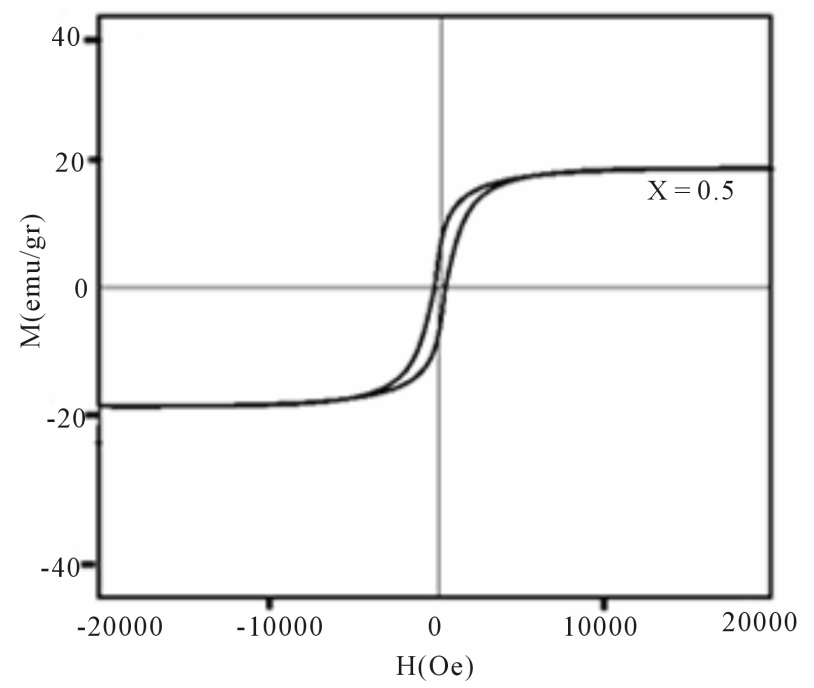

(d)

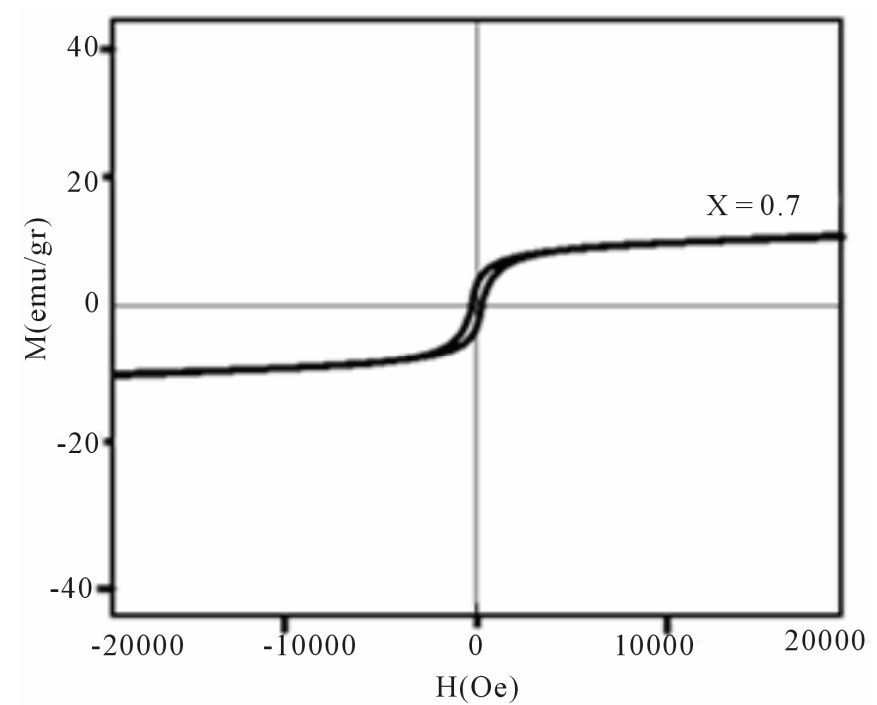

(e)

Figure 4. Magnetic hysteresis loops of $\mathrm{Ni}_{0.6} \mathrm{Co}_{0.4} \mathrm{Fe}_{2-x} \mathrm{Al}_{x} \mathrm{O}_{4}$ (a) $x=0$, (b) $x=0.1$, (c) $x=0.3$, (d) $x=0.5$, (e) $x=0.7$. 
Table 1. Dependence of particle size $D$, lattice constant Al content $x$.

\begin{tabular}{ccccc}
\hline$x$ & $\boldsymbol{D}(\mathbf{n m})$ & $\mathbf{a}(\AA)$ & $\mathbf{H}_{\mathbf{c}}(\mathbf{O e})$ & $\mathbf{M}_{\mathbf{s}}(\mathbf{e m u} / \mathbf{g r})$ \\
\hline 0 & 29 & 8.3024 & 420 & 61 \\
0.1 & 27 & 8.2918 & 380 & 58 \\
0.3 & 18 & 8.2636 & 330 & 42 \\
0.5 & 13 & 8.2502 & 250 & 18 \\
0.7 & 10 & 8.2336 & 180 & 10 \\
\hline
\end{tabular}

and the mentioned effect of reduced interaction after the increase of $\mathrm{Al}$ content.

\section{Conclusion}

The sol-gel auto-ignition technique yields nanocrystalline single phase ferrites. The XRD pattern shows the formation of single phase cubic spinel structure for all the samples. The lattice constant decreases with Al concentration. TEM analysis confirmed the measurements of nanosize by XRD data. Measured magnetic properties the room temperature magnetic hysteresis loops of our samples show that the coercive field and saturation magnetization decrease with increasing aluminum content, because the replacement of $\mathrm{Fe}^{3+}$ by $\mathrm{Al}^{3+}$ ions weaken the sublattice interaction and lowers the magnetic moments of unit cells. Also, this decrease is related to the decrease of particle size as the aluminum content is increased. Therefore, substitution of $\mathrm{Al}$ for $\mathrm{Na}$ can change these nano sized particles for soft magnetic materials application.

\section{REFERENCES}

[1] V. A. M. Baebes, "Progress in Spinel Ferrite Research," Elservier, Amesterdam, 1995.

[2] A. Amirabadizadeh, H. Farsi, M. Dehghani and H. Arabi, "Effect of Substitution of $\mathrm{Zn}$ for Mn on Size and Magnetic Properties of Mn-Zn Ferrite," Journal of Superconductivity and Novel Magnetism, Vol. 25, No. 8, 2012, pp. 2763-2765. doi:10.1007/s10948-01101259-5
[3] Z. P. Niu, Y. Wang and F. S. Li, "Magnetic Properties of Nano Crystalline Co-Ni Ferrite," Journal of Materials Science, Vol. 41, No. 17, 2006, pp. 5726-5730. doi:10.1007/S10853-006-0099-3

[4] M. George, A. M. Mary, S. S. Nair, P. A. Joy and M. R. Anantharaman, "Finite Size Effects on the Structural and Magnetic Properties of Sol-Gel Synthesized $\mathrm{NiFe}_{2} \mathrm{O}_{4}$ Powder," Journal of Magnetism and Magnetic Materials, Vol. 302, No. 1, 2006, pp. 190-195. doi:10.1016/j/jmmm.2005.08.029

[5] S. Giri, S. Gamanta, S. Maji, S. Gongli and A. Bahaumik, "Magnetic Properties of $\alpha-\mathrm{Fe}_{2} \mathrm{O}_{3}$ Nanoparticle Synthesized by a New Hydrothermal Method" Journal of Magnetism and Magnetic Materials, Vol. 288, No. 1-2, 2005, pp. 296-302. doi:10.1016/j/jmmm.2004.08.007

[6] H. P. Kluy and L. E. Alexnder, "X-Ray Crystalline and Amorphous Materials," Wily, New York, 1997.

[7] ASTM 10-325 (Ni-ferrite) National Burear of Standsards.

[8] E. Auzans, D. Zins, E. Blums and R. Massart, "Synthesis and Properties of Mn-Zn Ferrite Ferrofluids," Journal of Materials Science, Vol. 34, No. 6, 1999, pp. 1253-1260.

[9] S. S. Suryawanshi, V. V. Deshpande, V. B. Deshmukh, S. M. Kabur, N. D. Chaudhari and S. R. Sawanta, "XRD Analysis and Bulk Magnetic Properties of $\mathrm{Al}^{3+}$ Substituted Cu-Cd Ferrite," Materials Chemistry and Physics, Vol. 59, No. 3, 1999, pp. 199-203. doi:10.1016/S0354-0584(99)00046-2

[10] D. Mondelaers, G. Vanhoyland, H. Wallens and L. C.Van Pouke, "Synthesis of $\mathrm{ZnO}$ Nanopowder via an Aqueous Acetate-Citrate Gelation Method," Materials Research Bulletin, Vol. 37, No. 5, 2002, pp. 901-914. doi:10.1016/S0025-5408(02)00727-4

[11] V. Sepelak, D. Baabe, D. Mienert, D. Schultze, F. Krumeich, F. J. Litterst and K. D. Becker, "Evolution of Structure and Magnetic Properties with Annealing Temperature in Nanoscale High-Enrgy-Milled Nickel Ferrite," Journal of Magnetism and Magnetic Materials, Vol. 257, No. 2-3, 2006, pp. 377-386. doi:10.1016/j/S0304-8853(02)01279-9

[12] Luwreence Kumer, Manoranjan Kar, "Influence of $\mathrm{Al}^{3+}$ Ion Concentration of the Crystal Structure and Magnetic Anisotropy of Nanocrystalline Spinel Cobalt Ferrite," Journal of Magnetism and Magnetic Materials, Vol. 323, No. 15, 2011, pp. 2042-2048. doi:10.1016/j/jmmm.2011.03.010 